\title{
LA IRRELEVANCIA MORAL DE LA DIVERSIDAD CULTURAL
}

\author{
Paolo Comanducci \\ Universidad de Génova
}

RESUMEN. El autor analiza el ensayo de E. Garzón Valdés, «Cinco confusiones conceptuales acerca de la relevancia moral de la diversidad cultural» (1997), y pone de relieve la postura liberal, universalista, cosmopolita e ilustrada de Garzón, y sus críticas a los comunitaristas-liberales. Al final el autor se pregunta sobre las razones del escaso interés de Garzón por la cuestión de la fundación de la moral, y avanza al respecto una provocadora respuesta.

Palabras clave: Ernesto Garzón Valdés, diversidad cultural.

ABSTRACT. The author analyzes the article by E. Garzón Valdés, "Cinco confusiones conceptuales acerca de la relevancia moral de la diversidad cultural» (1997), and he underlines Garzón's liberal, universalist, cosmopolitan and enlightened position, and his criticism of liberal-communitarianism. In conclusion the author asks about the reasons of Garzón's lack of interest in the foundation of morals, and presents a provocative answer to that question.

Keywords: Ernesto Garzón Valdés, cultural diversity. 
Mi elección ha sido comentar el ensayo Cinco confusiones conceptuales acerca de la relevancia moral de la diversidad cultural, publicado por primera vez con este título en México en $1997^{1}$.

Las dos razones que explican mi elección son una de orden sencillamente biográfico, la otra de orden filosófico-político.

Se trata, en primer lugar, de un ensayo escrito pensando, también y sobre todo, en los problemas de la sociedad multiétnica mexicana, escrito para ser publicado y leído en México: y México para mí está fuertemente conectado a Ernesto (y por supuesto a Rodolfo VÁZQUEZ): fue Ernesto quien me hizo invitar por primera vez a México, fue en una colección co-dirigida por él («Ética, Filosofía del Derecho y Política», de la editorial Fontamara) en donde publiqué mi primer librito en castellano, fue en la cátedra que lleva su nombre, en el D.F., en la que he tenido el honor de dictar unas clases en 2006, ha sido en su compañía en la que han transcurrido algunos momentos muy agradables y estimulantes, en el D.F., entre museos, librerías y unos refrescos en la Casa de los azulejos.

En segundo lugar, si bien suele pasarme el estar de acuerdo con las posturas éticonormativas de Ernesto, en el caso de sus escritos sobre multiculturalismo (y este ensayo se encuentra entre ellos) mi coincidencia con él es tan grande que a veces me pregunto si las pequeñas cosas que escribí sobre estos asuntos unos años atrás no sean nada más que una torpe paráfrasis de sus artículos.

2. En este ensayo Ernesto presenta y critica cinco confusiones, circulantes en el debate contemporáneo sobre las relaciones entre ética y culturas. Las confusiones son las siguientes:

1. La confusión entre tolerancia y relativismo moral.

2. La confusión entre diversidad cultural y enriquecimiento moral.

3. La confusión entre identidad personal e identidad social.

4. La confusión entre unidad cultural y unidad institucional.

5. La confusión entre sujetos jurídicos y sujetos morales.

2.1. La primera confusión consiste en conectar conceptualmente — se trata de una conexión justificativa - tolerancia y relativismo moral, afirmando que «la tolerancia [...] estaría basada [...] en la aceptación del relativismo moral» (p. 234). Con esta última locución Ernesto designa la postura metaética ${ }^{2}$ según la cual las diversas culturas son inconmensurables desde un punto de vista ético, ya que no existe una ética universalmente válida, sino que cada cultura produce y desarrolla sus propios valores ${ }^{3}$. En tér-

${ }^{1}$ GARZÓn VALDÉs, 1997. Una versión muy similar de este trabajo salió el año anterior, siempre en México (GARZÓN VALDÉS, 1996). El ensayo ha sido reeditado en GARZÓN VALDÉS, 2001 (edición a la que haré referencia en lo que sigue), y ha sido también traducido al italiano por T. MAZZARESE (GARZÓN VALDÉs, 2003).

${ }^{2}$ El relativismo, así como decía BOBBIO del jusnaturalismo, no parece una ética, sino más bien una metaética.

3 «Relativismo moral» es una locución muy usada hoy en día sobre todo en el milieu de la iglesia de Roma. Siempre es preciso detectar con qué significado se usan locuciones como ésta, polisémicas y vagas, ya que sería claramente sorprendente, y quizás para algunos también blasfemo, afirmar que «Garzón y Ratzinger están ambos en contra del relativismo moral». 
minos del mismo concepto de tolerancia elaborado por Ernesto en otros ensayos, podríamos decir que, según los relativistas, el sistema normativo que justifica la tolerancia intercultural no estaría constituido por los principios de una ética normativa universal — como los principios liberales compartidos por Ernesto-, sino por un principio comunitarista que impone respetar igualmente, y sin límites, todas las culturas.

2.2. La segunda confusión consiste en pensar que el mero hecho de la diversidad entre las culturas produzca un enriquecimiento moral, así que cuantas más culturas mejor, desde un punto de vista ético. La raíz de esta idea equivocada, según Ernesto, se encuentra principalmente en la falta de distinción entre moral crítica y moral positiva.

2.3. La tercera confusión consiste en afirmar una conexión necesaria entre identidad individual e identidad social, en el sentido de que la primera dependería de la segunda, y de que la segunda tendría una primacía axiológica sobre la primera, ya que la pertenencia a una comunidad constituiría una necesidad básica para la identidad personal de cada individuo y tendría por sí misma valor moral.

2.4. La cuarta confusión consiste en afirmar la necesidad de una estrecha correspondencia entre unidad cultural y unidad institucional, en el sentido de que cada cultura debe tener su sistema jurídico y sus instituciones. En países multiculturales como México, entonces, para lograr esta correspondencia o bien se debería disolver el Estado unitario, o bien se debería practicar un «pluralismo jurídico» radical.

2.5. La quinta confusión consiste en hacer colapsar sujetos jurídicos y sujetos morales, y en afirmar por consecuente que ciertas entidades colectivas, que tienen subjetividad jurídica, tienen también subjetividad moral, son portadoras de intereses y titulares de derechos colectivos.

3. En éste, como en varios otros ensayos, el blanco de la crítica de Ernesto es la constelación formada por varios tipos de autores comunitaristas y multiculturalistas. Su estrategia es doble: $a$ ) rechaza rotundamente, casi sin argumentar, las posturas radicales, que se oponen frontalmente al liberalismo universalista y no comparten, de este último, ni los principios ni los valores supremos; $b$ ) mientras que discute las posturas menos radicales, que intentan compatibilizar liberalismo y comunitarismo, y en particular compatibilizar la defensa de los derechos humanos individuales con la defensa del valor moral de las distintas culturas.

La segunda estrategia es desarrollada en este ensayo a través de críticas de tres tipos diferentes, que constituyen la pars destruens de su trabajo. Se trata de críticas que tienen respectivamente que ver con: 1) la coherencia interna de las posturas criticadas; 2) su racionalidad instrumental; 3) sus efectos, por así llamarlos, perlocutivos.

3.1. El primer tipo de crítica apunta a subrayar las tensiones internas del comunitarismo liberal, y las antinomias que surgen, en el interior de esta posición, entre los principios liberales asumidos y la valoración moral de la diversidad cultural. Así, por ejemplo, Ernesto, discutiendo la segunda confusión, plantea — casi en passant_- el problema crucial, el dilema del comunitarismo liberal: ¿las culturas tienen valor moral por sí mismas, o sólo porque en ellas viven individuos, que sí tienen valor moral de por sí? Si se escoge el primer cuerno del dilema estamos inevitablemente fuera del liberalismo; si se escoge el segundo, las consecuencias resultan destructivas para la postura comunitarista-liberal. 
Otros casos de explícita contradicción interna aparecen analizando la cuarta confusión: el principio de clausura social (p. 258), compartido por algunos multiculturalistas, podría conllevar la prohibición de ejercer el derecho de exit y el de reingreso a la comunidad de pertenencia, que son ambos derechos humanos básicos.

En resumen, la postura criticada por Ernesto se enfrentaría inevitablemente con la alternativa o bien de abandonar los principios-clave del liberalismo o bien de abandonar sus específicos rasgos comunitaristas, y de volverse sencillamente liberal.

3.2. El segundo tipo de crítica apunta a subrayar la ineficiencia, la irracionalidad instrumental del comunitarismo liberal, ya que esta posición a menudo no logra realizar sus propósitos, que son muy similares a los de la postura liberal clásica.

En este terreno la argumentación crítica de Ernesto brinda ejemplos concretos en los que él intenta mostrar cómo la implementación de ideologías multiculturalistas podría frustrar, o ha de hecho frustrado, la obtención de los objetivos «liberales» que se quieren conseguir. Por ejemplo: el relativismo moral a veces impide la tolerancia interétnica y la igualdad de trato (primera confusión); atribuir valor moral a la pertenencia a una cultura puede determinar discriminaciones negativas, y violación de derechos básicos, de los individuos que no pertenecen a aquella cultura (tercera confusión); aceptar sin más el pluralismo jurídico tiene muchas veces como consecuencia la aceptación de prácticas que violan derechos fundamentales y la autonomía de las personas, como la circuncisión femenina (cuarta confusión).

3.3. Los posibles efectos «perversos» de las ideologías multiculturalistas son un hilo conductor de todo este ensayo: junto con algunos argumentos ad hominem, constituyen las razones más persuasivas — pero no necesariamente mejores desde otro punto de vista - en contra de las posturas criticadas por Ernesto. El núcleo del argumento de Ernesto suena así: implementar políticas multiculturalistas no sólo puede frustrar la realización de los objetivos deseados (crítica anterior), sino puede llevar a situaciones exactamente opuestas a las deseadas: estimular el fundamentalismo religioso, el fanatismo, la limpieza étnica e incluso el imperialismo.

4. Frente a cada una de las confusiones, Ernesto no sólo presenta una serie de críticas, sino también, en positivo, su solución a los distintos problemas. Es la pars construens del trabajo, en la que Ernesto escuetamente reafirma:

a) que la tolerancia intercultural debe tener límites, que están dados por una democracia constitucional, y debe ser justificada por razones-puente;

b) que lo que tiene valor moral de por sí no es la diversidad cultural, sino lo que satisface los intereses fundamentales de los individuos, conectados con sus necesidades básicas;

c) que hay buenas razones a favor del ideal cosmopolita, que le resulta claramente más atractivo respecto «a la vinculación telúrica o étnica incondicionada» (p. 268);

d) que instituciones políticas que garanticen derechos fundamentales a todos los individuos, e igualdad de trato y de oportunidades, son axiológicamente superiores a cualquier forma de pluralismo jurídico radical;

e) que los Estados constitucionales y democráticos de Derecho deben tratar el problema de las minorías realizando formas de gobierno autonómicas, y que los demás Estados deberían cuanto menos respetar los derechos fundamentales individuales. 
5. En resumen, Ernesto, en éste como en muchos otros ensayos, reafirma sus ideales universalistas y liberales. Yo diría que estos ideales tienen doblemente que ver con la idea de frontera. Por un lado afirman la fundamental relevancia moral de la frontera que separa cada individuo de los demás, la frontera de la autonomía. Por otro lado afirman la irrelevancia moral de las fronteras territoriales, étnicas, raciales, de género, de ser y de pertenecer, entre los individuos.

Él reafirma esos ideales, pero aquí como en general en casi toda su producción científica, no los fundamenta. Ernesto está claramente siempre interesado por cuestiones de ética normativa ${ }^{4}$, pero casi nunca se interesa por la cuestión metaética de la fundación de la moral. Mientras que, sin lugar a dudas, sí le apasionan otros asuntos metaéticos, como en particular el análisis de los conceptos morales.

Y entonces, en conclusión, me permito formular una pregunta: ¿por qué este desinterés por la fundación de la moral?

Por supuesto hay respuestas serias y probablemente acertadas. La manera de hacer filosofía de Ernesto es muy parecida a la de la ilustración — también el estilo literario lo acerca más que a todos a Voltaire-, y se podría hipotizar que Ernesto comparta con la ilustración la idea de que la razón nos muestra con claridad lo que es objetivamente justo, o al menos lo que es objetivamente injusto. Habría una tal evidencia de lo justo, que cada disquisición metaética sobre la fundación de los juicios morales sería para él una absoluta perdida de tiempo.

O bien se podría responder hipotizando que Ernesto nada quiera agregar sobre el punto, y que sencillamente acepte la fundación racionalista de la moral de origen kantiana.

Pero hay otra respuesta, probablemente descabellada, que presento mitad en serio y mitad en broma: ¿y si Ernesto fuese un emotivista sin saberlo? No digo que sea un emotivista sin confesarlo: aun si ha afirmado que la hipocresía tiene alguna fuerza civilizadora, no logro imaginarme a un hombre tan honesto que se hace el objetivista moral por razones estratégicas, porque declararse escéptico debilitaría la fuerza persuasiva de su argumentación moral. Hipócrita no, pero emotivista a pesar suyo quizás sí.

Al fin y al cabo ¿cuál es la diferencia entre un racionalista ilustrado que ve lo que es justo, y lo defiende con pasión, y un emotivista ilustrado que elige lo que en su opinión es justo, y lo defiende con pasión? Abismal diferencia, diría Manolo ATIENZA. Prácticamente ninguna, diría yo. Y Ernesto: ¿qué opina?

\section{BIBLIOGRAFÍA}

GARZÓN VALDÉS, E., 1996: «Algunas confusiones acerca de los problemas morales de la diversidad cultural», en L. OLIVÉ (comp.), Homenaje a Fernando Salmerón, México: Universidad Nacional Autónoma de México, pp. 81-109.

\footnotetext{
${ }^{4}$ Podríamos fácilmente definirlo un moralista, si esta palabra no hubiese ganado, en el uso, unas connotaciones negativas.
} 
- 1997: «Cinco confusiones conceptuales acerca de la relevancia moral de la diversidad cultural», Este país, 73: 59-68.

- 2001: «Cinco confusiones conceptuales acerca de la relevancia moral de la diversidad cultural», en E. GARZÓN VALDÉs, Filosofía, política, derecho. Escritos seleccionados, edición a cargo de J. DE LuCAS, Valencia: Universitat de València, pp. 233-271.

- 2003: «Cinque confusioni sul rilievo morale della diversità culturale», en E. GARZÓN VALDÉs, Tolleranza, responsabilità e Stato di diritto. Saggi di filosofia morale e politica, a cura di P. Comanducci e T. Mazzarese, Bologna, il Mulino. 